\title{
Context of Situation in Translation
}

\author{
Shuqin $\mathrm{Hu}$ \\ College of Foreign Languages, Qingdao University of Science and Technology, Qingdao, 266061, China \\ E-mail: shqhu@sina.com
}

\begin{abstract}
Context is an important concept in language study. According to the theory of systemic-functional linguistics, context of situation determines the meaning system of a text, and therefore translation is a process of reestablishing situational context in target language. Since no identical contexts exist, different translation strategies should be made. From this perspective, the problem of translation criteria can be explored in a new way.
\end{abstract}

Index Terms - context, context of situation, translation, preservation, shift

\section{CONTEXT AND ITS FUNCTION IN TRANSLATION}

The concept of context has been extensively studied by different linguists from different perspectives, such as pragmatics and systemic-functional linguistics. Among them, Halliday's approach shows clear advantages in translation study with its emphasis on language function, and therefore will be employed in the analysis of this paper.

In the framework proposed by Halliday, the concept of context consists of three strata: context of culture, context of situation and co-text. Context of culture and context of situation are outside of language itself. Co-text, also known as linguistic context, is certainly inside of language itself. There is a close interdependent relationship between language and context. Context determines and is constructed by the choice of language. On the one hand, language, when considered as a system--its lexical items and grammatical categories-is related to its context of culture. While on the other hand, the specific text and its component parts are related to its context of situation. To be specific, context of culture is related to genre, context of situation is related to register, and co-text to the discourse itself.

Context of situation consists of three aspects: field, tenor and mode. Field refers to what is happening, to the nature of social action that is taking place. It answers such questions as what it is that the participant is engaged in. Tenor refers to who is taking part, to the nature of the participants, their status and roles: what kind of role relationship obtain among the participants, including permanent and temporary relationships of one kind or another, both the types of speech role that they are taking on in the dialogue and the whole cluster of socially significant relationships in which they are involved. Mode refers to what part the language is playing, what it is that the participants are expecting the language to do for them in that situation: the symbolic organization of the text, the status that it has, and its function in the context, including the channel and also the rhetorical mode, what is being achieved by the text in terms of such categories as persuasive, expository, didactic and the like. Collectively the three aspects of situational context are called register.

Context of situation is closely related to various texts. Certain situational context asks for certain text and in return, certain text creates certain context. In the process of communication, the meaning system is largely determined by the three aspects of situational context: ideational meaning by field, interpersonal meaning by tenor and textual meaning by mode (Baker, 2000: 9). Studies in register analysis are of significance to translators. In the translation process, first, through the analysis of the linguistic feature of the SLT, its register can be identified and thus the determination of its context of situation is possible. Second, in the production of the TLT, the proper words and expressions in the TL should be chosen so that the corresponding context of situation can be reestablished in the TLT.

Seeking the equivalence of meaning is in fact seeking the equivalence of situational context. In translation, equivalence should not be based on one aspect of meaning (say ideational meaning); the translator must pursue equivalence of three aspects of meaning at the same time. Since the complete identity of situational context and meaning system between cultures is impossible, the complete equivalence is equally impossible. "Texts in different languages can be equivalent in different degrees (fully or partially equivalent in respects of context, of semantics, of grammar, of lexis etc.), and at different ranks (word-for-word, phrase-for-phrase, sentence-for-sentence)(baker, 2000: 6). Something is always lost in the process. Then what should be "preserved" and what should be "given up"? The translator is obliged to take these register variables into consideration in the process of translation rather than make decisions randomly or according to his/her personal favor. This concept throws new lights to the age-old debate concerning the translator's priorities: "literal" versus "free", "form" versus "content", "formal" versus "dynamic" equivalence, "semantic" versus "communicative" translating, "domestication" versus "foreignization" and translator's "visibility" versus "invisibility". In order to answer the above question, the translator has to turn to cultural context, since "what are relevant to translation are not only situational context but also cultural context. Language is a substantial but partial reflection of a culture." (Newmark, 1991:73). A language reflects the culture of a society, not only in its option of vocabulary, but also in its syntax and way of organizing ideas. In single context world, the author communicates with the source text readers who share the same cultural background knowledge with him/her. Therefore, 
they can co-operate with each other in the process of communication quite harmoniously. But the process of translation often breaks this harmony. "Translation is displaced and disjoined communication."( Neubert, 1992:10). In translation, the original text is deprived of its context and the information it carries is encoded in an entirely different language with an entirely different context. The reader may not be able to meet the expectation of the author, thus there comes information gap. The translator's job is to make up this gap and harmonize the communication. So Nida (1998:308) said, "For truly successful translating, biculturalism is even more important than bilingualism". When the cultural factors are incompatible in the target cultural context, the translator has to choose different strategies to cope with this cultural clash. Li Yunxing (2001:123) generalized several models in the translation of cultural factors: (1) the go-ahead model, transplanting them directly to the target text; (2) the block model, giving them up; (3) the annotation model, providing adequate explanation on the cultural factors; (4) the integration model, integrating the expressing modes of both cultures to create a new language form; (5) the adaptation model, replacing expression in the source culture with that in the target culture at the expense of the cultural meaning. In order to decide which model to choose, the translator still has to turn to the sociological parameters, which decide the discourse parameters (the register variables) in turn, namely, the participants, the setting and the purpose of translation. The following will give a detailed explanation of two different translation strategies concerning situational context (or register).

\section{PRESERVATION OF THE CONTEXT OF SituATION ACROSS LANGUAGES}

Usually, register is preserved in the translation process, as the overlook of any of the three variables: field, tenor and mode, will change the meaning of the SLT. For example,

Multiple reflections, mistakes, and diffraction effects at the edges of the sample are generally considered the main sources of errors. To enhance the measurement accuracy, special attention must be paid to the choice of the radiating elements, the design of the sample holder, and the sample thickness and location between the two radiating elements.

译文一：多重反射、不匹配，及样品边缘的散射反应，通常是产生误差的主要原因。为提高测试的准确度， 应特别注意辐射元素的选择，样品支架的设计以及两个辐射元素之间的样品的厚度和位置。

译文二: 多次反射、失配, 及样品边缘的衍射效应是误差的主要根源。为提高测量的精度, 特别注意辐射元 件的选择，样品支架的设计以及辐射元件间的样品的厚度和取向。

The SLT is a very formal technical text. The field determines the ideational meaning, which is realized by such lexical terms as multiple reflections, diffraction effects, measurement accuracy, radiating elements, location. Translation one is by a student of English major, while translation two by a graduate student of chemistry major. It is very obvious that translation two is more appropriate, since its translator have a better knowledge of the field in SLT.

Tenor decides interpersonal meaning. In the process of translation, the translator should pay close attention to the interpersonal relationship intended by the SLT, which is determined by its tenor. For example, , the character Kong Yiji in Luxun's famous short story Kongyiji, who was a pedantic old-type scholar, often used very formal words to show that he was different from not educated folks. When he distributed beans flavored with aniseed among children, he said “不 多不多！多乎哉? 不多也。”Yang Xianyi translated the sentence into "Not many, I do assure you. Not many, nay, not many at all." The use of nay reestablished the interpersonal relationship intended by Kong Yiji.

\section{SHIFT OF THE CONTEXT OF SitUATION ACROSS LANGUAGE}

In most cases, the register of the SLT should be preserved in the course of translation. However, in some cases, the field of the SLT and that of the TLT will remain the same, whereas the tenor needs to be shifted, which usually results in the shift of the mode. As both Gut and House point out, "the register appropriate in a given situation will vary between languages......As a corollary, register shifts would have to occur in the process of translation." (Fawcet, 1997:83).

A text is a form of communication that takes place between particular participants in a particular time and place, context of situation needs to be taken into account in the process of translation: its participants, medium, and other factors as well. The potential readers (the participant variables) are quite different in terms of their social class, education, age, taste etc. In order to meet the expectation of the target reader, the translator may have to adjust certain content or style of language, and this may result in the change of tenor, mode or even field. For example, Farewell to Arms, the title of a film was translated as “战地春梦” to cater to the taste of common people, while when taken as the title of the literary book, it may sounds vulgar to those whose aim is to get the literary spirit of Hemingway, thus it is changed into “永别了, 武器”.

The following is another example, which involves the change of mode in the process of translation. For example:

这里 3000 座奇峰拔地而起,形态各异,有的似玉柱神鞭,立地顶天; 有的像铜墙铁壁,巍然屹立; 有的如晃板垒卵, 遥遥欲坠; 有的若盆景古董,玲珑剔透, 神奇而又真实, 迷离而又实在, 不是艺术创造胜似艺术创造, 令人叹为观止"有 人将这段译成如下译文:

Translation one: 3000 crags rise in various shapes. They are like whips or pillars propping up the sky, or huge walls, solid and sound; or immense eggs pilled on an unsteady boarder; or miniature rocky or curios... Fantastic but actual, dreamy but real! They are not artistic works, but more exquisite than artistic works. One can not help marveling at the acme of perfection of Nature's creation. 
Translation two: 3000 crags rise in various shapes-pillars, columns, walls, shaky egg stacks and potted landscapes...conjuring up fantastic and unforgettable images.

The SLT is a scenery introduction typical of Chinese. By using many elaborate adjectives, parallel structures, and idioms, it caters to the taste of Chinese readers and meets their mode of thinking. While in an English text of the same type plain and clear language is expected to be used. Therefore, translation two is more appropriate.

In conclusion, the situational context theory can be used to explain many seemingly opposite concepts in translation such as foreignization and domestication, faithfulness and naturalness etc. The translator has to analyze the specific situational context of both the SLT and the TLT. Only by doing this can s/he strike a balance between these dual concepts and make proper decisions on her/his specific translating strategies. This viewpoint is in accordance with the "skopos theory" in Germany. One of its scholars, Christiane Nord (see 2001:34) proposes "adequacy" rather than "equivalence" as the utmost aim and evaluating standard of translation.

\section{REFERENCES}

[1] Baker, M. (2000). In Other Words - a Course Book on Translation. Beijing: Foreign Language Teaching and Research Press.

[2] Halliday, M.A.K. \& Hason, R. (1976).Cohesion in English. London: Longman.

[3] Halliday, M.A.K. (1999). The notion of Context in Language education. In Text and Context in Functional Linguistics. Philadelphia: John Benjamins Publishing Company.

[4] Nord, C. (2001). Translating as a Purposeful Activity—Functionalist Approach Explained. Shanghai: Shanghai Foreign Language Education Press.

[5] Newmark, P. (1991). About Translation. Multilingual Matters ltd.

[6] Neubert, A. \& Gregory M. S. (1992). Translation as Text. The Kent State University Press.

[7] Nida, E. A. (1998). Language, Culture and Translating. Inner Mongolia University Press.

[8] Fawcett, Peter. (1997). Translation and Language: Linguistic Theories Explained. Manchester: St. Jerome Publishing.

[9] Li, Yunxing. (2001). Yupian Fanyi Yinlun (Introducing Theories of text Translation).Beijing: China Translation and Publishing Corporation.

[10] Zhang, Delu. (1998). Gongneng Wenti Xue(Functional Typology). Jinan: Shandong Education Press.

[11] Huang, Guowen. (1988). Yupian Fenxi Gaiyao(Essentials of Text Analysis). Changsha: Hunan Education Publishing House.

[12] Huang, Zhonglian. (2002).Variation Translation. Foreign Languages Research.3.

[13] Zhang, Meifang \& Huang, Guowen. (2002).A Text Linguistic Approach to Translation Studies. Chinese Translators Journal,3.

Shuqin Hu was born in Linyi, China in 1978. She received his M.A. degree in linguistics from Ocean University of China, China in 2003 .

She is currently an instructor in the College of Foreign Languages, Qingdao University of Science and Technology, Qingdao, China. Her research interests include translation theory and practice. 